\title{
Management of blunt hepatic and splenic trauma in children
}

Stanley Crankson

$\mathrm{T}$

Trauma is a major cause of morbidity and mortality in children. With blunt abdominal trauma, the most commonly injured organs are the liver and the spleen. ${ }^{1}$ The management of blunt hepatic and splenic injuries has evolved over the past three decades from an emergency operation to a nonoperative approach. The nonoperative management of splenic injuries in children became acceptable because of the significant incidence and seriousness of postsplenectomy sepsis, and the frequent complications associated with non-therapeutic laparotomies. ${ }^{2}$ Subsequently, nonoperative management of hepatic injuries showed similar success to the results of splenic injuries. ${ }^{3,4}$ Thus, in the hemodynamically stable child, nonoperative management of hepatic and/or splenic injuries has become the current standard of care. However, in the hemodynamically unstable child or the child with signs or symptoms of peritonitis, an immediate operation is necessary. This report is a retrospective review of children with blunt hepatic and/ or splenic injuries managed at King Fahad National Guard Hospital, Riyadh, Saudi Arabia.

\section{Patients and Methods}

The medical records of all children up to 12 years of age inclusive with blunt hepatic and splenic injury admitted from January 1997 through December 2001 were reviewed. The data collected included age, sex, mechanism of injury, organ and associated injuries, pediatric trauma score (PTS), management, complications and mortality.

The Pediatric Trauma Score (PTS) of the children was calculated retrospectively using a formula incorporating the following physiologic variables on initial presentation: weight, airway, systolic blood pressure, central nervous system status, skeletal injury and severity of open wounds. ${ }^{6}$ The PT values range from -6 to +12 . A score $\leq 8$ is designated major trauma; a score $\geq 9$ is designatd minor trauma.

\section{Results}

There were 64 children, 49 males (77\%) and 15 females (23\%). The age range was 1 to 11 years (mean, 5.2 years). Thirty children (47\%) were between 4 and 6 years and 45(70\%) were under 6 years. Motor vehicle accident (MVA) was the most common mechanism of injury in 58 children (91\%), with 44 as pedestrians and 14 as passengers. Six children sustained injuries from falls, 4 from height, 1 from a bicycle and 1 from falling onto the floor. The hepatic and splenic injuries were graded according to the American Association for Surgery of Trauma Organ Injury Scaling using either CT scan or laparotomy findings. ${ }^{5}$

The distribution of hepatic injury and splenic injuries by grade are summarized in Table 1. Isolated hepatic and splenic injuries occurred in 5 and 2 children, respectively. The associated injuries included 50 thoracic (78\%), 24 skeletal (38\%), 21 head and neck (33\%) and 15 other in-
From King Fahad National Guard Hospital, Department of Surgery, Riyadh, Saudi Arabia

Correspondence: Stanley Crankson, MD Consultant, Pediatric Surgeon Department of Surgery - MC 1446 King Abdulaziz Medical CityRiyadh

King Fahad National Guard

Hospital

P.O. Box 22490

Riyadh 11426

Kingdom of Saudi Arabia

Tel No: 966-1-2520088

Fax No: 966-1-2520051

cranksons@yahoo.com

Accepted for publication August 2005

Ann Saudi Med 2005;25(6):492-495 
traabdominal (23\%) injuries (Table 2). Twenty-eight children (44\%) had a PTS range from 1 to 8 , two (3\%) below zero and 34 (53\%) had a PTS above 8.

Sixty-one children (95\%) were hemodynamically stable and had no signs or symptoms of peritonitis. All had an abdominal CT, which revealed hepatic and/or splenic injuries. Only one child with Grade IV splenic injury failed nonoperative management because of persistent hemorrhage, which required a splenectomy. The success rate of nonoperative management was $98 \%$. Three children required immediate laparotomy, one for gastric perforation and 2 for bleeding from severe hepatic injuries (Grade IV and $\mathrm{V})$.

One child managed nonoperatively had a Grade IV liver injury that was complicated by a left hepatic duct biliary leak. After diagnosis by CT and HIDA scan, the leak was treated by endoscopic retrograde cholangiopancreatography (ERCP) and endostenting. Two children died from severe hepatic injuries (Grade IV and V) and a third child with Grade III splenic injury succumbed to a severe head injury. Thus the mortality rate was $4.7 \%$.

\section{Discussion}

Blunt abdominal trauma is a common injury in childhood, with the liver and spleen being the most frequently injured solid organs. ${ }^{1}$ The most common mechanism of injury in blunt abdominal trauma is MVA and in this study, most victims were pedestrians..$^{7-11}$ MVA was the cause of the hepatic and/or splenic injury in $91 \%$ children; $69 \%$ of the total injuries were pedestrians. Poor driving and unsupervised children playing in the street seem to be the main reasons for these pedestrian injuries. ${ }^{11}$ Most of the injured children in this review were boys younger than 9 years of age. This experience is similar to other reports from Saudi Arabia. ${ }^{7-11}$ Injured passengers who are unrestrained were thrown out of the vehicle or against the dashboard or windscreen.

The initial management of a child with blunt abdominal trauma should follow the standard trauma resuscitation guidelines. Immediate life threatening injuries should be identified and treated promptly. A hemodynamically unstable child with hemoperitoneum or with signs of abdominal injury should undergo laparotomy. Any child who is hemodynamically stable or who is rapidly stabilized after initial resuscitation should be managed nonoperatively. Children with severe solid organ injury should have aggressive resuscitation and nonoperative therapy before committing to laparotomy. Nonoperative management
Table 1. Distribution of liver and spleen injuries in 64 children with blunt trauma.

\begin{tabular}{l|c|c|c|c|c|c|c}
\hline Grade & I & II & III & IV & V & VI & TOTAL \\
\hline Liver & 17 & 12 & 6 & 3 & 1 & 0 & 39 \\
\hdashline Spleen & 12 & 4 & 8 & 3 & 0 & - & 27 \\
\hline
\end{tabular}

Table 2. Associated injuries.

\begin{tabular}{l|c}
\hline Thoracic $(n=50,78 \%)$ & 23 \\
\hline Lung contusion & 12 \\
\hline Hemo/pneumothorax & 11 \\
\hline Rib fracture & 3 \\
\hline Clavicle fracture & 1 \\
\hline Cord contusion & \\
\hline Skeletal (n=24, 38\%) & 15 \\
\hline Femur fracture & 6 \\
\hline Pelvis fracture & 2 \\
\hline Humerus fracture & 1 \\
\hline Tibia fracture & \\
\hline Head and Neck $(n=21,33 \%)$ & 17 \\
\hline Head injury & 2 \\
\hline Cervical fracture & 2 \\
\hline Mandible fracture & \\
\hline Abdominal $(n=15,23 \%)$ & 1 \\
\hline Renal injury & \\
\hline Adrenal hematoma & \\
\hline Retroperitoneal hematoma & \\
\hline Gastric Perforation & \\
\hline Pancreatic injury & \\
\hline & \\
\hline
\end{tabular}

of splenic and hepatic injuries was successful in 98\% of children in this review, which compares favorably with other studies. ${ }^{2,12-15}$ The success of nonoperative management of solid organ injury is dictated primarily by hemodynamic stability, which is the child's physiologic response to resuscitation, and not by the grade of the injury. ${ }^{16}$ However, children with highgrade injuries are more likely to present with hemodynamic instability. Those who oppose nonoperative management of solid organ injury argue that there may be complications such as abscesses, delayed hepatic bleeding, bilomas and missed intestinal injury. ${ }^{16}$ However, these complications are uncommon 
in children. In this review, there was a biliary leak in a child with hepatic trauma that was managed by a nonoperative approach using ERCP and endostenting. Noninvasive procedures such as CT guided drainage, intrahepatic trans-catheter techniques or laparoscopy are currently available for treating any complications occurring during nonoperative management of hepatic injury. ${ }^{17}$

CT has revolutionized the management of the multiply injured child. Imaging of the abdomen and pelvis is mandatory in a child with suspected blunt abdominal trauma on the basis of clinical examination or by laboratory analysis of blood or urine, or who has an impaired level of consciousness with a high risk of abdominal trauma as suggested by the mechanism of injury. ${ }^{13}$ Using CT, the severity of the organ injury (hepatic and/or splenic) is determined by the American Association for the Surgery of Trauma Organ Injury Scaling guidelines. ${ }^{5}$ The main disadvantage of CT is a difficulty with diagnosing intestinal injury. The presence of pneumoperitoneum without an extraabdominal or iatrogenic cause, extraluminal air in the retroperitoneum, free intraperitoneal fluid without solid organ injury, focal areas of thickening of the bowel wall and mesentery and leakage of contrast material from the bowel are all highly suggestive of intestinal injury. ${ }^{13,18}$ Focused abdominal sonography for trauma (FAST) is gaining popularity as a reliable method for the evaluation of trauma patients, particularly for the hemodynamically unstable. ${ }^{19}$ Its advantages are that it is non-invasive and can be performed in minutes, that it can identify fluid in the peritoneal cavity or pericardial sac and is not expensive. Ultrasound (US) is inaccurate in determining intraperitoneal organ injuries, but is reliable in detecting free intraperitoneal fluid. ${ }^{20}$ The place of US in the initial evaluation of children with blunt abdominal trauma is still not well established because the presence of fluid in the abdomen does not imply that surgery is necessary. The detection of free intraabdominal fluid requires further diagnostic evaluations. ${ }^{20}$

In this review, blunt abdominal trauma was associated with multisystem injuries. Eighty-nine percent of the children had concomitant injuries, $87 \%$ being thoracic. Because $91 \%$ of the children sustained MVA injuries either as pedestrians or as unrestrained passengers, thoracoabdominal, skeletal and head injuries were common.

The mortality rate in this review was $4.7 \%$. Two children died from severe hepatic (Grade IV, V) injury despite aggressive resuscitation and laparotomy. Severe hepatic injury is associated with a high mortality rate especially if the child undergoes emergency operation. ${ }^{16}$ It is not surprising that one child with uncontrollable hepatic hemorrhage died during surgery and the other in the immediate postoperative period. PTS predicts the severity of injury and the potential for mortality. ${ }^{6,21}$ Children with a PTS between 0 and 8 have an increased mortality unless care is expeditious and appropriate. The mortality is $100 \%$ with PTS below zero but 0\% when greater than eight. Fifty-three percent of the children in this review had a PTS greater than 8, 3\% were below zero and 44\% were between 1 and 8 . The decreased mortality may be related to the high PTS and the non-lethal concomitant injuries since most were thoracic lesions, mainly lung contusions. Aggressive resuscitative measures may also have assisted in the survival of these injured children.

In conclusion, most pediatric blunt hepatic and splenic injuries are MVA-related with the majority of the victims being auto-pedestrians. The most common concomitant injuries are thoracic, skeletal and head trauma. Nonoperative management of hepatic and/or splenic trauma is successful in 98\% of children. However, severe hepatic injuries that require immediate laparotomy are associated with significant mortality. Measures aimed at preventing MVA-related injuries would decrease the incidence of abdominal trauma in children in Saudi Arabia. 


\section{References}

1. Benya EC, Bulas DI. Splenic injuries in children after blunt abdominal trauma. Semin Ultrasound CT MR. 1996; 17: 170-176.

2. Bond SJ, Eichelberger MR, Gotschall CS, Sivit CJ, Randolph JG. Nonoperative management of blunt hepatic and splenic injury in children. Ann Surg. 1996; 223: 286-289.

3. Cywes $\mathrm{S}$, Rode $\mathrm{H}$, Millar AJ. Blunt liver trauma in children: nonoperative management. $J$ Pediatr Surg. 1985; 20: 1-18.

4. Leone RJ Jr, Hammond JS. Nonoperative management of pediatric blunt hepatic trauma. $A m$ Surg. 2001; 67: 138-142.

5. Moore EE, Cogbill TH, Jurkovich GJ, Shackford

SR, Malangoni MA, Champion HR. Organ Injury Scaling: Spleen and Liver (1994 Revision). J Trau ma. 1995; 38: 323-324.

6. Tepas JT III, Mollitt DL, Talbert JL, Bryant M The pediatric trauma score as a predictor of injury severity in the injured child. J Pediatr Surg. 1987 22: 14-18.

7. Tamimi TM, Daly M, Bhatty MA, Lufti AHM Causes and types of road injuries in Asir Province Saudi Arabia 1975-1977: Preliminary study. Saudi Med J. 1980; 1: 249-256.

8. Al-Tukhi MH. Road traffic accidents: Statistics and data comparing Gulf countries and Riyadh area. Ann Saudi Med. 1990; 11: 1-3.

9. Evbuomwan I. Paediatric trauma admissions in the Sakaka Central Hospital, Al Jouf Province, Saudi Arabia. Saudi Med J. 1994; 15: 435 -437.

10. Al Salem AH, Qaisaruddin S. Thoracic and abdominal trauma in children. Ann Saudi Med. 1999; 19: 58-61.

11. Crankson SJ, Fischer JD, Al Rabeeah AA, Al Jadaan SA. Pediatric thoracic trauma. Saudi Med J. 2001; 22: 117-120.

12. Jacobs IA, Kelly K, Valenziano C, Pawar J, Jones C. Nonoperative management of blunt splenic and hepatic trauma in the pediatric population: Significant differences between adult and pediatric surgeons? Am Surg. 2001; 67: 149-154. 13. Shankar KR, Lloyd DA, Kitteringham L, Carty HML. Oral contrast with computed tomography in the evaluation of blunt abdominal trauma in children. Br J Surg. 1999; 86: 1073-1077.

14. Haller JA Jr, Papa P, Drugas G, Colombani P Nonoperative management of solid organ injuries in children. Is it safe? Ann Surg. 1994; 219: 625631.

15. Eichelberger MR, Mangubat EA, Sacco WJ Bowman LM, Lowenstein AD. Outcome analysis of blunt injury in children. J Trauma. 1988; 28: 11091117

16. Pryor JP, Stafford PW, Nance ML. Severe blunt hepatic trauma in children. J Pediatr Surg. 2001; 36: 974-979.

17. Carrillo EH, Spain DA, Wohltmann CD, et al. Interventional techniques are useful adjuncts in nonoperative management of hepatic injuries. $J$ Trauma. 1999; 46: 619-624.

18. Cox TD, Kuhn JP. CT scan of bowel trauma in the pediatric patient. Radiol Clin North Am. 1996; 34: 807818.

19. Boulanger BR, Rozycki GS, Rodriguez A. Sonographic assessment of traumatic injury. Future developments. Surg Clin North Am. 1999; 79: 12971316.

20. Akgur FM, Aktug T, Olguner M, Kovanlikaya A, Hakguder G. Prospective study investigating routine usage of ultrasonography as the initial diagnostic modality for the evaluation of children sustaining blunt abdominal trauma. J Trauma. 1997; 42: 626-628.

21. Tepas JJ III, Ramenofosky ML, Mollitt DL, Gans BM, Di Scala C. The pediatric trauma score as a predictor of injury severity: an objective assessment. J Trauma. 1988; 28: 425-429. 